\title{
Dynamic Analysis of Composite Rotors
}

\author{
S. P. SINGH \\ Assistant Professor, Department of Mechanical Engineering, Regional Engineering College, Jalandhar, INDIA
}

\section{K. GUPTA}

Professor of Mechanical Engineering, Indian Institute of Technology, New Delhi, INDIA

\begin{abstract}
An outline of formulation based on a layerwise beam theory for unbalance response and stability analysis of a multi mass, multi bearing composite rotor mounted on fluid film bearings is presented. Disc gyroscopics and rotary inertia effects are accounted for. Material damping is also taken into account. The layerwise theory is compared with conventionally used equivalent modulus beam theory. Some interesting case studies are presented. The effect of various parameters on dynamic behavior and stability of a composite rotor is presented.
\end{abstract}

Key Words: Composite shafts; rotordynamics; driveshafts; rotors

\section{INTRODUCTION}

S tudies on composite shafts started [Zinberg and Symmonds, 1970] in 1970's, with two viable materials, boron/epoxy and carbon/epoxy. The two US patents [Worgan and Smith, 1978 and Yates and Rezin, 1979] and the work of Spencer and McGee [1984] indicate that around that time preliminary hurdles in design of subcritical composite drive shafts and in their practical application to rotating machinery were overcome. Subsequently, Lim and Darlow [1986] have investigated the possibility of supercritical operations in order to achieve larger reduction in weight of the rotor system. Hetherington et. al. [1990] demonstrated the feasibility of a supercritical composite helicopter power transmission shaft. They have shown the possibility of reduction of $60 \%$ in the total system weight of the tail drive rotor. Hoffman [1989] considered an automotive application and showed that carbon fibre becomes a necessity in order to have a critical balance between torque, diameter, length and natural frequency. Bauchau [1983] carried out

Postal Address: K. Gupta, Professor, Department of Mechanical Engineering, Indian Institute of Technology, Hauz Khas, New Delhi, India $-110016$ the detailed optimization studies on high speed graphite/ epoxy shafts and considered design of tapered composite shafts.

Rotordynamic aspects have also received some attention. Zorzi and Giordano [1985] conducted rotordynamic experiments on an aluminium shaft as well as on a composite shaft. They reported excellent matching between theoretical and experimental results. Reis et. al. [1987] estimated the critical speeds of composite shafts by finite element method and studied the effect of bending stretching and shear normal coupling on the same. Singh and Gupta [1995] estimated the critical speeds and unbalance response by a layerwise theory. They have shown that a layerwise theory gives more realistic stress field in tubular composite shaft. Detailed theoretical dynamic analysis and rotordynamic experiments on composite shafts have been carried out by Singh [1992]. Singh and Gupta reported the free damped vibrations of composite tubes by EMBT [1994a] and of a composite cylindrical shell by shell theory [1994b].

Stability analysis of composite rotors mounted on fluid film bearings has not been studied till date, possibly for the reason that such an application has not been considered as yet. It is, however, felt that with increasing use of composite rotors in future, studies on stable operation of such rotors mounted on fluid film bearings will be of 
importance, particularly in respect of the comparative role of various sources of damping in rotor system.

The present paper analyses the results of the equivalent modulus beam theory (EMBT) and the layerwise beam theory (LBT) derived from a shell theory in order to understand their limitations and relative advantages. An outline of the formulation based on Ritz method for unbalance response and stability analysis of a multimass composite rotor (with tubular shaft) mounted on general eight coefficient bearings is then presented. Case studies of rotors mounted on rolling element and fluid film bearings are presented in order to bring out the salient features of the analysis.

\section{FORMULATION}

The formulation for equivalent modulus beam theory as well as the layerwise theory is based on Ritz method wherein the admissible functions are assumed for the displacement components and the algebraic eigenvalue problem is formulated. Only, the outline of the method is presented here and the detailed steps of the formulation are reported separately [Singh and Gupta, 1995].

The EMBT for a composite rotor, essentially determines the equivalent modulus of the tubular shaft in the longitudinal direction and the equivalent longitudinal shear modulus. The expression for equivalent longitudinal modulus is found on the basis that circumferential stress is zero in the tube [Bauchau, 1983]. The moduli can be expressed in terms of the tube parameters and the invariants of the material, as

$$
E=\frac{\left(4\left(U_{1}-U_{5}\right)\left(U_{5}+U_{3} \gamma\right)-\beta^{2} U_{2}^{2}\right)}{U_{1}-\beta U_{2}+\gamma U_{3}}
$$

where $U_{1}, U_{2}, U_{3}, U_{4}, U_{5}$ are laminate invariants.

$$
\begin{aligned}
& \gamma=\sum_{i=1}^{n} \frac{t_{i}}{t} \cos 4 \alpha_{i} \\
& \beta=\sum_{i=1}^{n} \frac{t_{i}}{t} \cos 2 \alpha_{i}
\end{aligned}
$$

and equivalent shear modulus

$$
G=U_{5}-U_{3} \gamma
$$

After the equivalent moduli are determined, the conventional Timoshenko beam theory is extended in two dimensions (Figure 1) and the additional rotor effects are included. The cross-coupled unsymmetric terms are

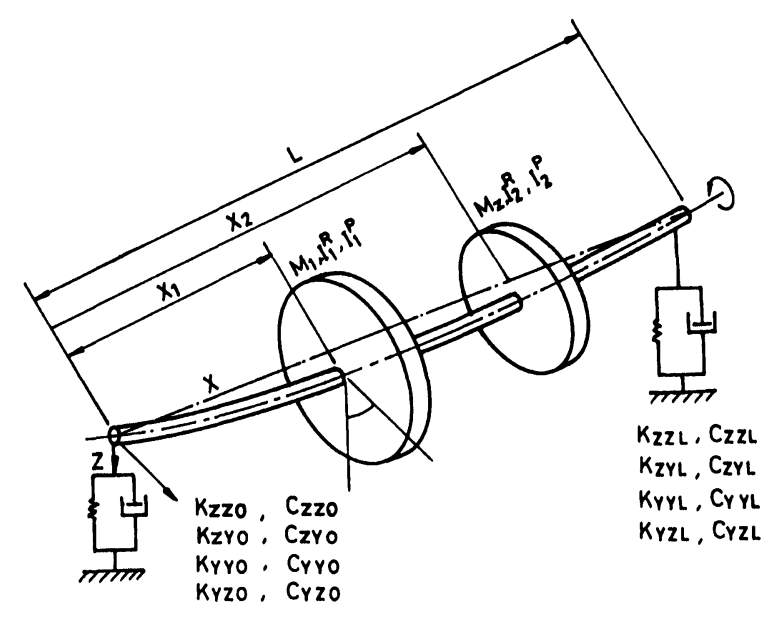

FIGURE 1 A composite rotor as per EMBT

treated separately in accordance with the variational formulation keeping the force quantity in-tact and differentiating with respect to the corresponding displacement coefficients only. These non-symmetric cross-coupled effects arise from bearing stiffness, bearing damping, gyroscopic effects and hysteretic material damping.

Material damping is assumed in the form of discrete damping coefficients (viscous $c_{r}$ and hysteretic $h_{r}$ ) at the mass locations. The dissipation function is calculated on the basis of effective displacements $w^{e}\left(x_{r}\right)$ and $v^{e}\left(x_{r}\right)$ which represent the total rotor deflection minus the deflection due to the rigid body motion.

Combining the contributions from all the components of strain energy and kinetic energy, the final expression for Lagrangian, ( $\tilde{\mathrm{L}})$ taking into account the effects of shear deformation, rotary inertia and gyroscopic effects is as given in equation (3). In the expression for $\tilde{L}$, the time dependent common term has been removed. The Lagrangian in general is complex valued and gives rise to simultaneous equations with complex coefficients. These equations can be expressed in the form of standard quadratic eigen value problem, which can then be solved by the use of matrix decoupling procedure [Singh, 1992].

$$
\begin{aligned}
& \tilde{L}=\frac{1}{2} \int_{0}^{L} E I\left\{\left(\frac{\partial \alpha}{\partial x}\right)^{2}+\left(\frac{\partial \beta}{\partial x}\right)^{2}\right\}+G K\left\{\left(\frac{\partial v}{\partial x}-\beta\right)^{2}\right. \\
& \left.+\left(\frac{\partial w}{\partial x}-\alpha\right)^{2}\right\} d x \\
& -\frac{\nu^{2}}{2} \int_{0}^{L} T I\left\{\left(w^{2}+v^{2}\right)+R I\left(\alpha^{2}+\beta^{2}\right)\right\} d x
\end{aligned}
$$




$$
\begin{aligned}
& -\frac{1}{2} v^{2} \sum_{r}\left[M_{r}\left(w\left(x_{r}\right)^{2}+v\left(x_{r}\right)^{2}\right)+I_{r}^{R}\left(\alpha\left(x_{r}\right)^{2}+\beta\left(x_{r}\right)^{2}\right)\right. \\
& \left.-I_{r}^{P} i \nu \omega\left\{\overline{-\alpha\left(x_{r}\right)} \beta\left(x_{r}\right)+\overline{\beta\left(x_{r}\right)} \alpha\left(x_{r}\right)\right\}\right] \\
& +\frac{1}{2}\left\{K_{Y Y O} v(0)^{2}+K_{Z Z O} w(0)^{2}+K_{Y Y L} v(L)^{2}+K_{Z Z L}^{2} w(L)^{2}\right\} \\
& +\overline{\left.K_{Y Z O^{w}} w\right)} v(0)+\overline{K_{Y Z L} w(L)} v(L)+\overline{K_{Z Y O} v(0)} w(0) \\
& +\overline{K_{Z Y L} v(L)} w(L)+i v\left[\frac { 1 } { 2 } \left\{c_{Y Y O} v(0)^{2}+c_{Z Z O} w(0)^{2}\right.\right. \\
& \left.+c_{Y Y L} v(L)^{2}+c_{Z Z L} w(L)^{2}\right\}+\overline{c_{Y Z O} w(0)} v(0) \\
& \left.+\overline{c_{Z Y O} v(0)} w(0)+\overline{c_{Y Z L} w(L)} v(L)+\overline{c_{Z Y L} v(L)} w(L)\right] \\
& +i v \sum_{r}\left[\frac{1}{2}\left(c_{r}+h_{r}\right)\left(w^{e}\left(x_{r}\right)^{2}+v^{e}\left(x_{r}\right)^{2}\right)\right. \\
& \left.-\omega h_{r}\left\{\overline{w^{e}\left(x_{r}\right)} v^{e}\left(x_{r}\right)+\overline{v^{e}\left(x_{r}\right)} w^{e}\left(x_{r}\right)\right\}\right]
\end{aligned}
$$

\section{Layerwise Theory}

In layerwise theory, inplane displacements for each individual layer are assumed separately. The displacement continuity at each interface is maintained (Figure 2). However, different laminae may have different slopes. Because of more realistic displacement field, layerwise theory is expected to yield more accurate results. Layerwise beam theory is obtained by reduction from a layerwise shell theory after imposing the condition of zero cross-sectional distortion [Singh and Gupta, 1995]. This is achieved by using a relationship between circumferential displacement $v$ and radial displacement $w$. The resulting displacement field to be used in shell theory such that only flexural modes ensue, is

$$
\bar{u}_{z i}=u_{i}(x) \cos \theta
$$

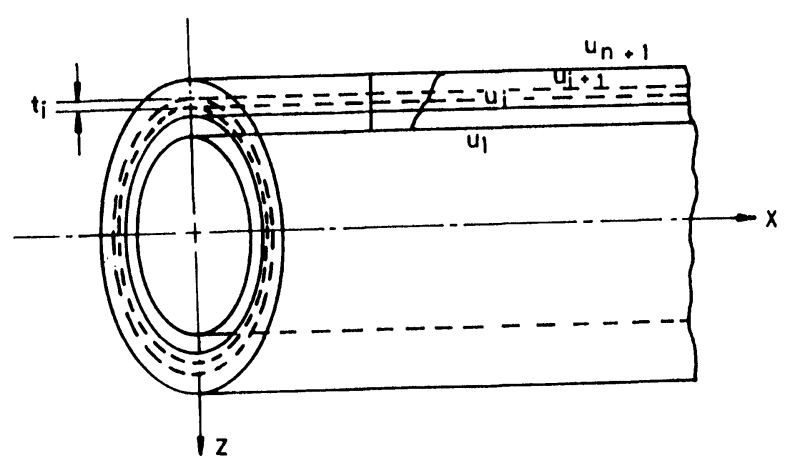

FIGURE 2 Displacement field as in layerwise beam theory

$$
\begin{aligned}
& \bar{v}_{z i}=-w(x) \sin \theta \\
& \bar{w}=w(x) \cos \theta
\end{aligned}
$$

Using these conditions in the shell theory expressions, the strain energy and kinetic energy are expressible in terms of $u_{i}(x)$ and $w(x)$ only, which essentially becomes the displacement field for LBT. Integrating with respect to $\mathrm{z}_{\mathrm{i}}$ and $\theta_{\mathrm{i}}$ and after performing the algebraic simplifications, the strain energy due to deformation of the laminated tubular composite beam can be expressed as

$$
\begin{aligned}
& \tilde{U}=\frac{\pi}{2} \sum_{i=1}^{n} \int_{0}^{L}\left[\left\{\left(u_{i+1, x}^{2}+u_{i, x}^{2}+u_{i+1, x} u_{i, x}\right) R_{i} t_{i} / 3+\left(u_{i+1, x}^{2}\right.\right.\right. \\
& \left.\left.-u_{i, x}^{2}\right) / 12\right\} Q_{11 i}+\left\{\left(u_{i+1}+u_{i}\right)^{2} a_{i} / 4+\left(u_{i+1}^{2}-u_{i}^{2}\right)(1\right. \\
& \left.+a_{i} R_{i} / t_{i}\right)+\left(u_{i+1}-u_{i}\right)^{2}\left(a_{i} R_{i}^{2}-R_{i} t_{i}\right) / t_{i}^{2}+w_{x}^{2} R_{i} t_{i} \\
& \left.+w_{, x}\left(u_{i+1}+u_{i}\right) t_{i}\right\} Q_{66 i}+\left\{w_{, x}^{2} R_{i} t_{i}+\left(u_{i+1}^{2}+u_{i}^{2}\right.\right. \\
& \left.\left.\left.-2 u_{i} u_{i+1}\right) R_{i} / t_{i}+2\left(w_{, x} u_{i+1}-w_{, x} u_{i}\right) R_{i} t_{i}\right\} Q_{55 i}\right] d z_{i} d x
\end{aligned}
$$

$$
\text { where } a_{i}=\ln \left\{\frac{\left(R_{i}+t_{i} / 2\right)}{\left(R_{i}-t_{i} / 2\right)}\right\}
$$

The kinetic energy is,

$$
\begin{aligned}
& T=\frac{v^{2} \pi}{2} \int_{0}^{L} \sum_{i=1}^{n} \rho_{i}\left[\frac{R_{i} t_{i}}{3}\left(u_{i+1}^{2}+u_{i}^{2}+u_{i+1} u_{i}\right)+2 w^{2} R_{i} t_{i}\right. \\
& \left.+\frac{t_{i}^{2}}{12}\left(u_{i+1}^{2}-u_{i}^{2}\right)\right] d x
\end{aligned}
$$

For adaption to rotor problem, the displacement field for a layered tubular beam is extended in two perpendicular directions and additional rotor effects are incorporated in the same way as was done for EMBT. The Lagrangian $\tilde{L}=\tilde{U}-\tilde{T}$ is made stationary with respect to solution coefficients. The resulting equations are expressible in the form of quadratic eigenvalue problem with complex coefficients which can be solved for eigenvalues and eigenvectors. Whereas, the eigenvalues give the whirl frequency and modal damping ratio also providing information about the stability of the rotor, the eigenvectors can be used to calculate the modal stresses by the combined use of series summation function, strain displacement and stress strain relations.

\section{RESULTS AND DISCUSSION}

The rotor dynamic studies were conducted on rotors supported on rolling element bearings as well as fluid 
film bearings. Rolling element bearings are modelled as simple rigid supports and the beam functions for a simply supported beam are chosen as the solution function. For fluid film bearing, a separate set of functions satisfying the complementary boundary conditions (allowing for deflections at bearing supports) was chosen. The rotordynamic characteristics such as critical speeds, whirl frequencies, damping ratios, unbalance response and threshold of stability are studied.

\section{Composite Test Rotor on Rigid Supports}

One of the primary gains of layerwise formulation has been the incorporation of the bending-stretching coupling due to which the effect of stacking scheme of the winding angles is properly taken into account. Some interesting results have been obtained for different stacking sequences. The primary objective is to estimate the extent of difference in results obtained by varying the stacking sequence in a composite rotor of typical dimensions and parameters given below,

\section{Material: Carbon/Epoxy Density $=1500 \mathrm{~kg} / \mathrm{m}^{3}$}

length $L=1.0 \mathrm{~m}$; mean radius $R=0.05 \mathrm{~m}$; total thickness $t=4 \mathrm{~mm}$ comprising of 4 layers.

$E_{11}=130 \mathrm{GPa} ; E_{22}=10 \mathrm{GPa}$;

$G_{12}=G_{13}=G_{23}=7 \mathrm{GPa} ; v_{12}=0.25$.

In one such study, the stacking scheme consists of four layers, three of them at $45^{\circ}$ and one of $0^{\circ}$ (axially wound). The position of $0^{\circ}$ layer was varied from inner to outer radius and the corresponding changes in flexural frequency values given in Table 1 can be explained as under.

The layer with $0^{\circ}$ orientation has longitudinal modulus, much larger than those with $45^{\circ}$ fibre angle. As a result, the position of $0^{\circ}$ layer, largely governs the bending strain energy of the tube. In other words, the radius at which $0^{\circ}$ layer is located, primarily determines the effective radius of the tube. It is also known that for a thin walled tube the flexural frequency is approximately directly proportional to the mean radius, more

TABLE 1

Flexural frequency for different stacking schemes using LBT $(\mathrm{Hz})$

\begin{tabular}{llll}
\hline Stacking Scheme & 1st & 2nd & 3rd \\
(From Inner Radius) & Flexural & Flexural & Flexural \\
\hline $0^{\circ}, 45^{\circ}, 45^{\circ}, 45^{\circ}$ & 305 & 1134 & 2313 \\
$45^{\circ}, 0^{\circ}, 45^{\circ}, 45^{\circ}$ & 310 & 1152 & 2349 \\
$45^{\circ}, 45^{\circ}, 0^{\circ}, 45^{\circ}$ & 315 & 1170 & 2386 \\
$45^{\circ}, 45^{\circ}, 45^{\circ}, 0^{\circ}$ & 321 & 1180 & 2422 \\
EMBT Value & 314 & 1166 & 2376 \\
\hline
\end{tabular}

precisely the effective radius. And the effective radius can be assumed to vary with the position of the $0^{\circ}$ layer, which explains the variation of natural frequency by LBT. For EMBT, the mean radius $\mathrm{R}$ is used for calculating the bending strain energy which implies that the effect of all the layers is assumed to be positioned at mean radius. Thus, EMBT is incapable of predicting the effect of stacking sequence on natural frequency. It can be noticed from Table 1, that the EMBT value lies in between the values of two stacking schemes where $0^{\circ}$ layer is near the mean radius with thickness extending on either side of it.

In another case, a two layered shaft was considered. The orientation of both the layers was changed such that the two layers remain cross-ply to each other. The nature of variation of the first two natural frequencies is shown in figure 3. It can be noticed that with change in fibre angle of outer layer from $0^{\circ}$ to $45^{\circ}$, the flexural frequencies decrease, primarily due to decrease in the equivalent longitudinal modulus. This effect is also depicted from EMBT results. However, the EMBT curve is symmetric with respect to $45^{\circ}$ configuration, unlike the LBT curve. This is because, EMBT can not take into account, the bending stretching coupling whose effect is different at ply angles less than and/or greater than $45^{\circ}$.

At $45^{\circ}$, the results from the two theories match almost exactly. This establishes the fact that if the fibre angle in all the layers is same, the laminate effectively behaves as single layer and EMBT gives accurate results for such a configuration. In general, the EMBT value for any combination lies in between the two extreme values determined by layerwise theory with reversal of fibre angle in the two layers.

Using the layerwise theory, the modal stress distribution inside the thickness of the laminate can be obtained. It is shown by detailed analysis [Singh and Gupta 1995], that the stress distribution obtained by LBT is more accurate and realistic because of inherent limitation of EMBT mentioned above.

\section{Composite Test Rotor on Fluid Film Bearings}

The damped natural frequencies, damping and unbalance response studies were conducted on the test rotor with same fixed parameters but with a lumped mass and supported on fluid film bearings. A disc of mass $=7.0$ $\mathrm{kg}$, lateral Inertia $=0.013 \mathrm{~kg}-\mathrm{m}^{2}$ and polar moment of inertia $=0.026 \mathrm{~kg}-\mathrm{m}^{2}$ is assumed to be located at $0.35 \mathrm{~m}$ from one end.

The fibre angles and sequences are symmetric with respect to the mid-plane $(\theta,-\theta,-\theta, \theta)$. Here three values of $\theta$ as $30^{\circ}, 45^{\circ}$ and $60^{\circ}$ are chosen. Comparison 

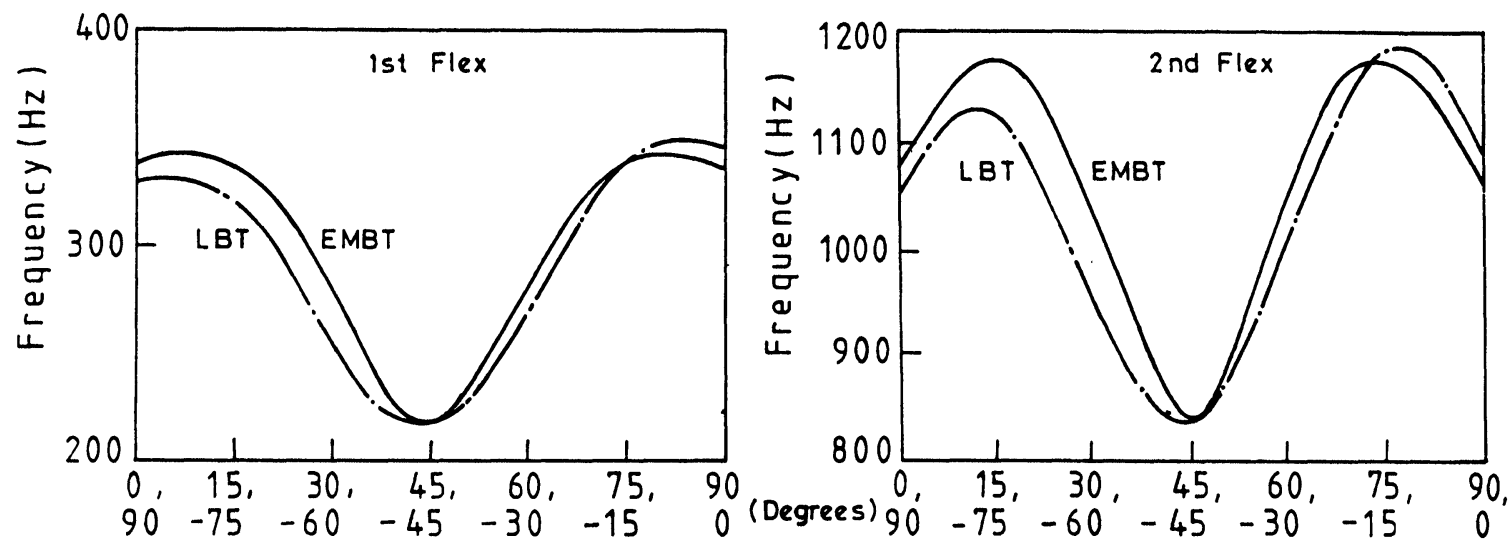

FIGURE 3 Flexural frequencies for a two layered shaft

of results for these cases also depicts the effect of fibre angle. The following journal bearing parameters are selected keeping in view the small mass of the rotor $(\approx$ $9.3 \mathrm{~kg}$.)

$$
\begin{aligned}
& D=4 \mathrm{~cm} ; L=2 \mathrm{~cm} ; L / D=0.5 \\
& \text { Dynamic Viscosity }=6 \times 10^{-3} \mathrm{Ns} / \mathrm{m} \\
& \text { Diametral Clearance }=0.1 \mathrm{~mm}
\end{aligned}
$$

The unsymmetric location of the lumped mass would result in unequal reactions at the two bearings. Thus bearing stiffness and damping coefficients, being dependent on bearing reaction, will also be different for the two bearings. The first four modal frequencies and damping ratios at different speeds of rotation, for the test rotor supported on fluid film bearings are given in Figures 4 to 6 for ply angles $30^{\circ}, 45^{\circ}$ and $60^{\circ}$ respectively. These results have been obtained by EMBT. However, it was also established from analysis that for this configuration the layerwise theory would as well give the same results. The modes 1 and 2 correspond to rigid body modes while mode numbers 3 and 4 represent the flexural modes. A few general observations can be made from figures 4 to 6 , results of which are summarised in Table 2.

The synchronous whirl line (SWL) does not intersect the rigid body modes ( 1 and 2 ), implying thereby that these modes are not excited by the unbalance in the rotor. The flexural modes 3 and 4 intersect the SWL line. The intersection of SWL with mode 3 curve (forward Whirl) gives the first critical speed. The frequency values for mode number 1 and 2, which correspond to rigid body modes increase with increase in speed, while their damping factors decrease. The primary reason for this can be traced to high value of damping at low rpm, which reduces the natural frequency. With high damping some of the modes may even get suppressed. The flexural modes, however do not vary much. Mode 3 registers a decrease and then starts increasing with increasing rotor speed. Beyond a certain rotor speed, mode 3 frequency becomes higher than mode 4 frequency. This change over occurs at about $9000 \mathrm{rpm}$ for $30^{\circ}$, and at about 7300 $\mathrm{rpm}$ and $6200 \mathrm{rpm}$ for $45^{\circ}$ and $60^{\circ}$ fibre angles respectively. Mode 4 registers a steady marginal decrease with increasing speed.

Damping ratios in modes 1 and 2 decrease rapidly with increasing speed. Damping ratios in these rigid body modes are very high at lower speeds. In flexural

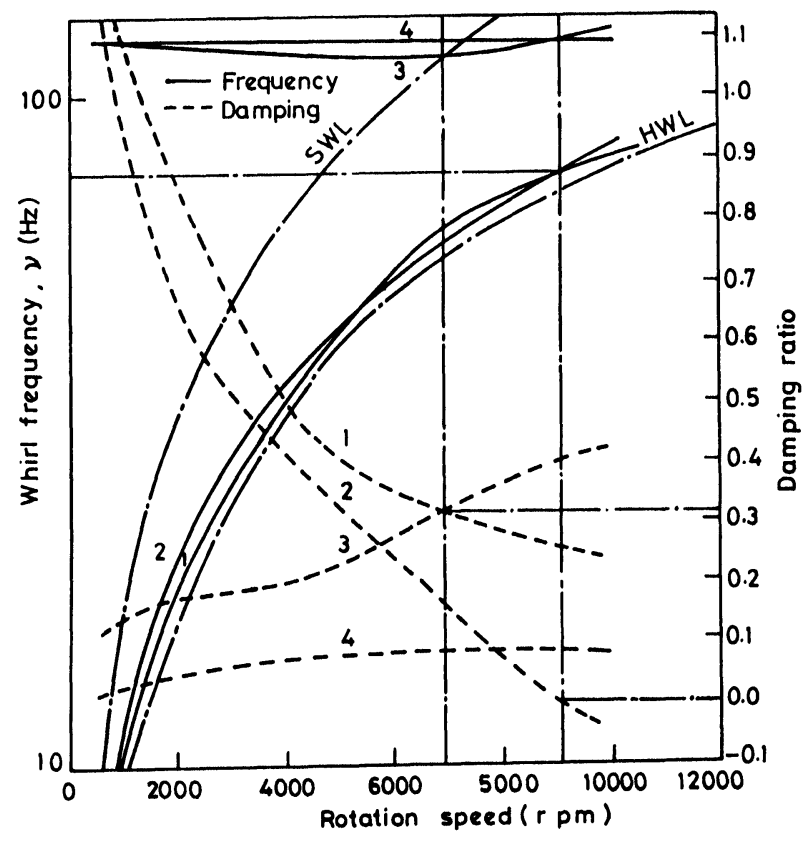

FIGURE 4 Campbell plot for $30^{\circ}$ composite rotor on FF-bearings 
TABLE 2

Results for the composite rotors on fluid film bearings

\begin{tabular}{lllllll}
\hline Fibre angle & $\begin{array}{l}\text { FW Intersection } \\
(\mathrm{Hz})\end{array}$ & $\begin{array}{l}\text { BW Intersection } \\
(\mathrm{Hz})\end{array}$ & $\begin{array}{l}\text { Critical speed } \\
(\mathrm{rpm})\end{array}$ & $\begin{array}{l}\text { Damping at critical } \\
(\mathrm{FW})\end{array}$ & $\begin{array}{l}\text { Threshold speed } \\
(\mathrm{rpm})\end{array}$ & Whirl at Threshold \\
\hline $30^{\circ}$ & 114.43 & 119.53 & 7100 & 0.311 & 9034 & 76.28 \\
$45^{\circ}$ & 74.96 & 80.1 & 4800 & 0.177 & 7447 & 62.71 \\
$60^{\circ}$ & 57.88 & 61.28 & 3675 & 0.108 & 6174 & 52.5 \\
\hline
\end{tabular}

modes the damping ratios increase with increase in speed. Increase in damping ratio of mode 3 is more dominant in all the three cases of fibre angles.

With increase in speed of rotation, the damping factor value of first mode transforms from positive to negative value. This marks onset of instability. The speed corresponding to zero damping factor is the threshold speed, which is about 9034,7447 and $6174 \mathrm{rpm}$ for $30^{\circ}, 45^{\circ}$ and $60^{\circ}$ fibre angles respectively. The ratio of whirl frequency to the threshold speed is slightly larger than 0.5 . Also, the damping factor at the critical speed is more for $30^{\circ}$ shaft $(0.31)$ and less for $45^{\circ}(0.17)$ and $60^{\circ}(0.1)$. In these results, the only source of damping is from the bearing. So, the role of the material, in results of figures 4 to 6 , is limited to the extent of providing its share of strain energy due to flexure of composite tubular shaft. It may however be noted that $60^{\circ}$ shaft possesses higher value of material damping than $45^{\circ}$ or $30^{\circ}$ shafts, due to higher contribution from the matrix material. Thus the introduction of material damping in rotordynamic analysis may alter the trend of damping ratio at critical speed, with fibre angle.

The unbalance response plots for the test rotors of all fibre angles are given in Figure 7. The response values have been obtained under the action of total unbalance of $0.01 \mathrm{~kg}-\mathrm{cm}$, at the location of the lumped mass $(x=0.35$ $\mathrm{m})$. The major axis and the phase angle $\delta$ (the orientation of the major axis of the orbital ellipse with respect to horizontal direction) are plotted. The speeds corresponding to peak response are slightly higher than the value predicted by intersection of SWL with natural frequency line in Figures 4 to 6 . This is in accordance with the general observations for a damped single degree of freedom system under unbalance excitation, where the frequency corresponding to the peak response is slightly higher than the damped natural frequency calculated from free vibration analysis. For the case of rotor on fluid film bearings, the shaft whirl orbits are elliptical at all

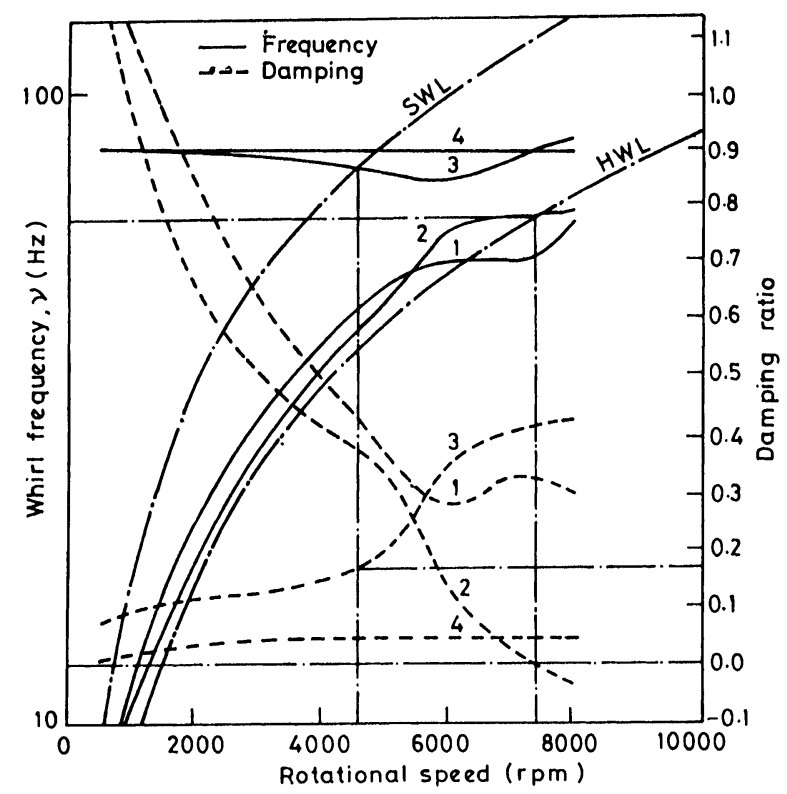

FIGURE 5 Campbell plot for $45^{\circ}$ composite rotor on FF-bearings

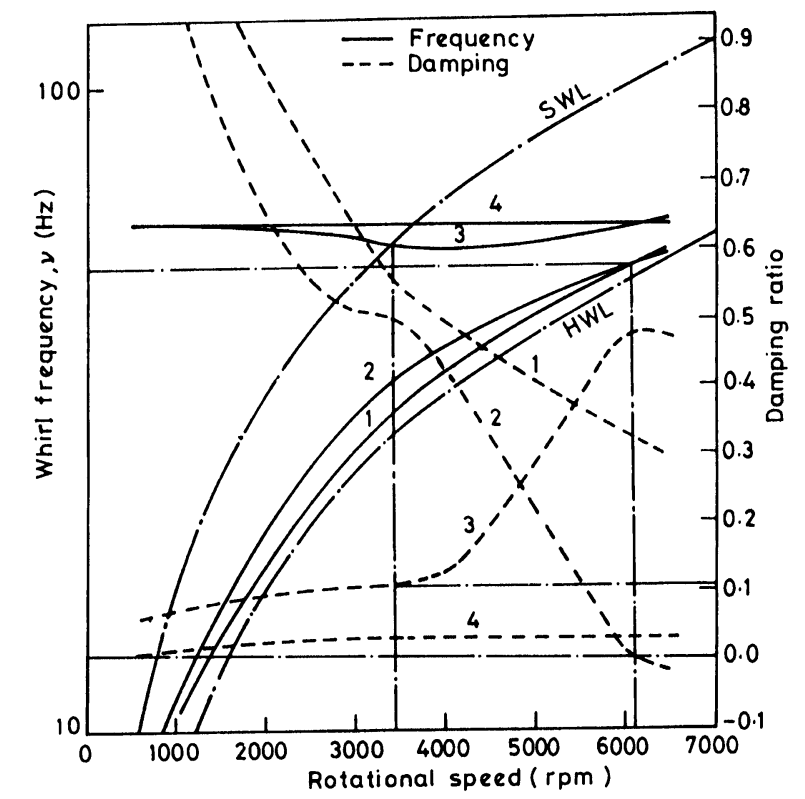

FIGURE 6 Campbell plot for $60^{\circ}$ composite rotor on FF-bearings 


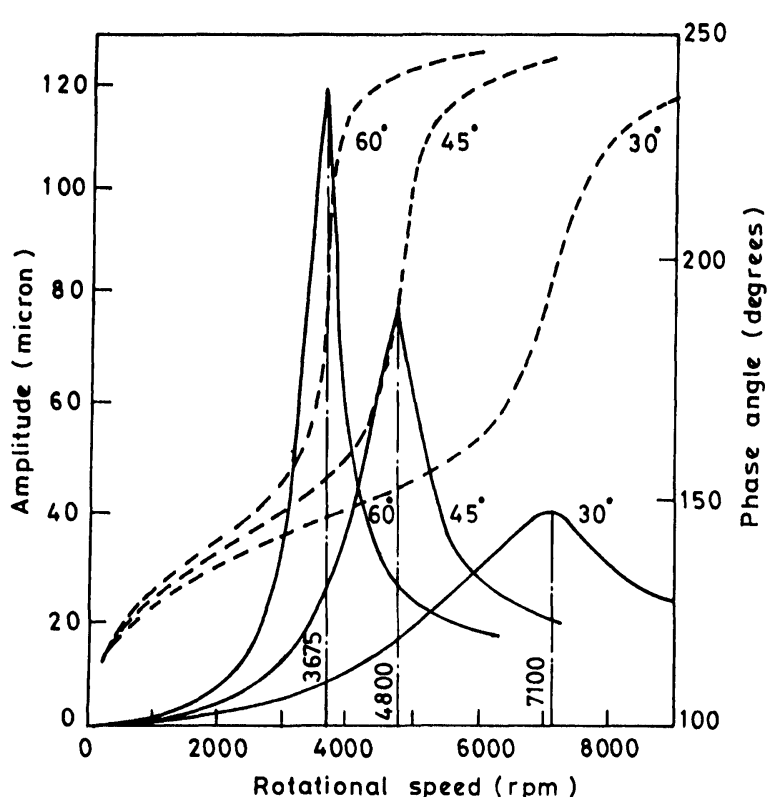

FIGURE 7 Unbalance response plots for composite rotors on FFbearings.

speeds. Their orientations however change as the rotor speed crosses the critical speed. For the case of rotor supported on rigid bearings, circular orbit was predicted.

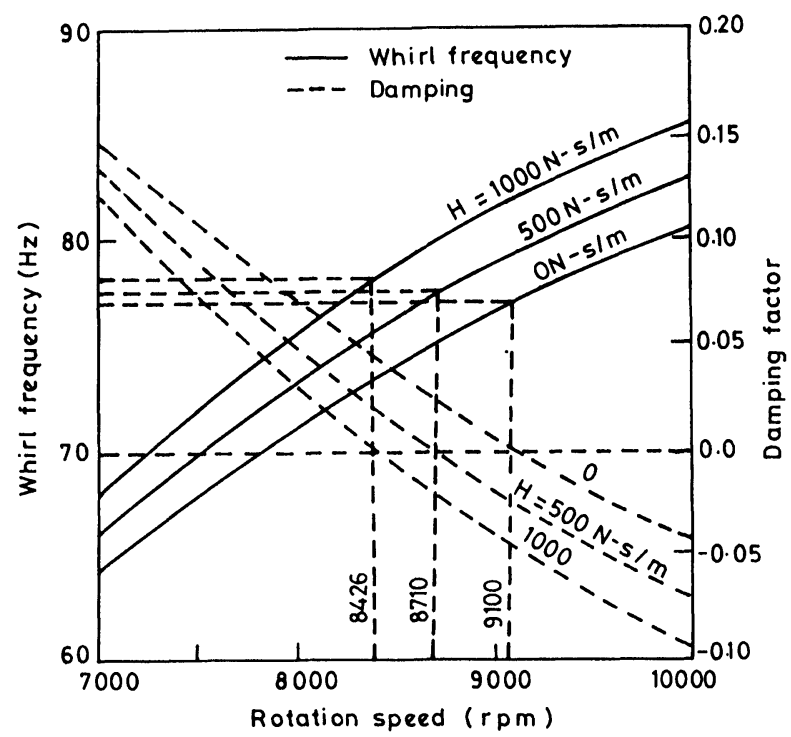

FIGURE 8 Effect of internal damping on instability of composite rotor.

\section{Effect of Internal Damping}

The shaft internal damping has two primary sources (i) material damping and (ii) internal friction of joints and fittings etc. In the simple conventional models for internal damping, discrete damping coefficients are assumed at the places, where disc mass is located. Both viscous and hysteretic damping coefficients may be assumed and used separately, independent of each other. Ehric [1964] has established that while the viscous damping tends to stabilize the system, the hysteretic internal damping has the tendency to cause instability. Elaborate studies of the combined effects of different kinds of damping acting simultaneously in the rotor system, have been conducted in literature, for metallic rotors. Because of same model being used in the present formulation, the qualitative effects of material damping would be same. The differences would only be of quantitative nature, since material damping in composite shafts is of higher order. Figure 8 shows the stability plot for the $30^{\circ}$ composite test rotor with different values of internal damping $H$. With increase in internal damping value, the damping factor has decreased, thus leading to reduction of threshold speed. On the other hand, the whirl frequency at threshold speed is shown to increase with increase in internal damping coefficient.

However, it may be noted that in Figure 8, the damping factor of only that mode, which causes instability, is plotted. The effect of internal damping on different modes may be different. Results as regards the effect of internal damping for test rotor are summarised in Table 3. For example, it was noted that damping factor corresponding to flexural mode increased with the introduction of material damping being, $0.311,0.531$ and 0.555 for hysteretic damping coefficient of 0,500 and $1000 \mathrm{Ns} / \mathrm{m}$ respectively. Also, because of elliptical response orbits, the critical speed and the response may also be affected by the introduction of internal damping. The first critical speed values, (intersection with SWL) change marginally with internal damping as shown in Table 3.

\section{CONCLUSIONS}

Comparative study of results from EMBT and LBT shows that the simplest theory i.e., the EMBT is quite adequate for estimation of critical speeds and unbalance response but may predict inaccurate results for unsymmetric stacking sequences. For these sequences the layerwise theory gives better results. The modal stresses in the thickness of the tube wall can be aptly determined by the use of layerwise theory. Role of material damping in vibrations of a rotor system is analysed. The hysteretic 
TABLE 3

Effect of internal damping on whirl frequencies and threshold speed

\begin{tabular}{cllll}
\hline Internal Damping (Ns/m) & Threshold Speed (rpm) & FW Intersection $(\mathrm{Hz})$ & Damping Factor & Whirl at Threshold (Hz) \\
\hline 0 & 9034 & 114.43 & 0.3166 & 76.28 \\
500 & 8710 & 114.05 & 0.5316 & 77.17 \\
1000 & 8426 & 113.45 & 0.5554 & 78.00 \\
\hline
\end{tabular}

form of damping reduces the threshold speed and results in an increase of damping factor at the critical speed. The effect of fibre angle on critical damping factor (damping factor at critical speed) of a rotor, provided by the bearing damping is different from that provided by the material damping. Material damping effect in the present formulation is incorporated by using discrete coefficients as is used for metallic rotors. However, more detailed studies need to be conducted on participation of material damping using refined modelling taking into account the damping in continuum of the shaft material.

\begin{tabular}{|c|}
\hline Nomenclature \\
\hline$E I=$ \\
\hline$G K=$ \\
\hline $\begin{array}{l}\rho= \\
T I=\end{array}$ \\
\hline$R I=$ \\
\hline $\begin{array}{l}M_{r}= \\
\mathrm{I}_{r}^{\mathrm{R}}=\end{array}$ \\
\hline $\mathrm{I}_{r}^{\mathrm{P}}=$ \\
\hline $\begin{array}{l}x_{r}= \\
K_{Y Y}, K_{Y Z}, K_{Z Z}, \\
K_{Z Y} \\
C_{Y Y}, C_{Y Z}, C_{Z Z} \\
C_{Z Y} \\
R_{i}= \\
t_{i}= \\
u_{i}=\end{array}$ \\
\hline $\begin{array}{l}v= \\
w= \\
\alpha= \\
\beta= \\
\theta=\end{array}$ \\
\hline
\end{tabular}

\section{References}

Bauchau, O. A., 1983. Optimal Design of High Speed Rotating Graphite/Epoxy Shafts, Journal of Composite Materials, Vol. 17, pp. 170-181.

Ehric, F. F., 1964. Shaft Whirl induced by Rotor Internal Damping, ASME Journal of Applied Mechanics, Vol. 12, pp. 279-282.

Hetherington, P. L., Kraus, R. F. and Darlow, M. S., 1990. Demonstration of a Super Critical Composite Helicopter Power Transmission Shaft, Journal of American Helicopter Society, pp. 23-28.

Hoffman, W., 1989. Fibre Composite in the Driveline, Plastics and Rubber International, Vol. 14, No. 5, pp. 46-49.

Lim, J. W., and Darlow, M. S., 1986. Optimal Sizing of Composite Power Transmission Shafting, Journal of American Helicopter Society, Vol. 31, No. 1, pp. 75-83.

Henrique, L. M., dos Reis., Goldman, R. B. and Verstrate, P. H., 1987. Thin walled Laminated Composite Cylindrical Tubes-Part III, Critical Speed Analysis, ASTM Journal of Composite Technology and Research, Vol. 9, No. 2, pp. 58-62.

Singh, S. P., 1992. Some Studies on Dynamics of Composite Shafts, Ph. D thesis, Mech. Engg. Deptt., IIT, Delhi.

Singh, S. P., and Gupta, K., 1994a. Free Damped Flexural Vibration Analysis of Composite Cylindrical Tubes using Beam and Shell Theories, Journal of Sound and Vibration., Vol. 172, No. 2, pp. 171-190.

Singh, S. P., and Gupta, K., 1994b. Damped Free Vibrations of Layered Composite Cylindrical Shells, Journal of Sound and Vibration., Vol. 172, No. 3, pp. 191-209.

Singh, S. P., and Gupta, K., 1995. Composite Shaft Rotordynamic Analysis using a Layerwise theory, to appear in Journal of Sound and Vibration.

Spencer, B., and McGee, J., 1984. Design Methodology for a Composite Drive Shaft, Advanced Composites, Conference Proceedings, Dearborn, Michigan, Dec. 2-4, pp. 69-82.

Worgan, G., and Smith, D., 1978. Carbon Fibre Drive Shafts, US Patent No. 4089190.

Yates, D., and Rezin, D., 1979. Carbon Fibre Reinforced Composite Driveshafts, US Patent no. 417626.

Zinberg, H., and Symmonds, M. F., 1970. The Development of an Advanced Composite Tail Rotor Drivershaft, Presented at $26^{\text {th }}$ Annual National Forum of American Helicopter Society, Washington D.C.

Zorzi, E. S., and Giordano, J. C., 1985. Composite Shaft Rotordynamic Evaluation, ASME Design Engineering Conference on Mechanical Vibrations and Noise, ASME Paper no. 85-DET-114. 

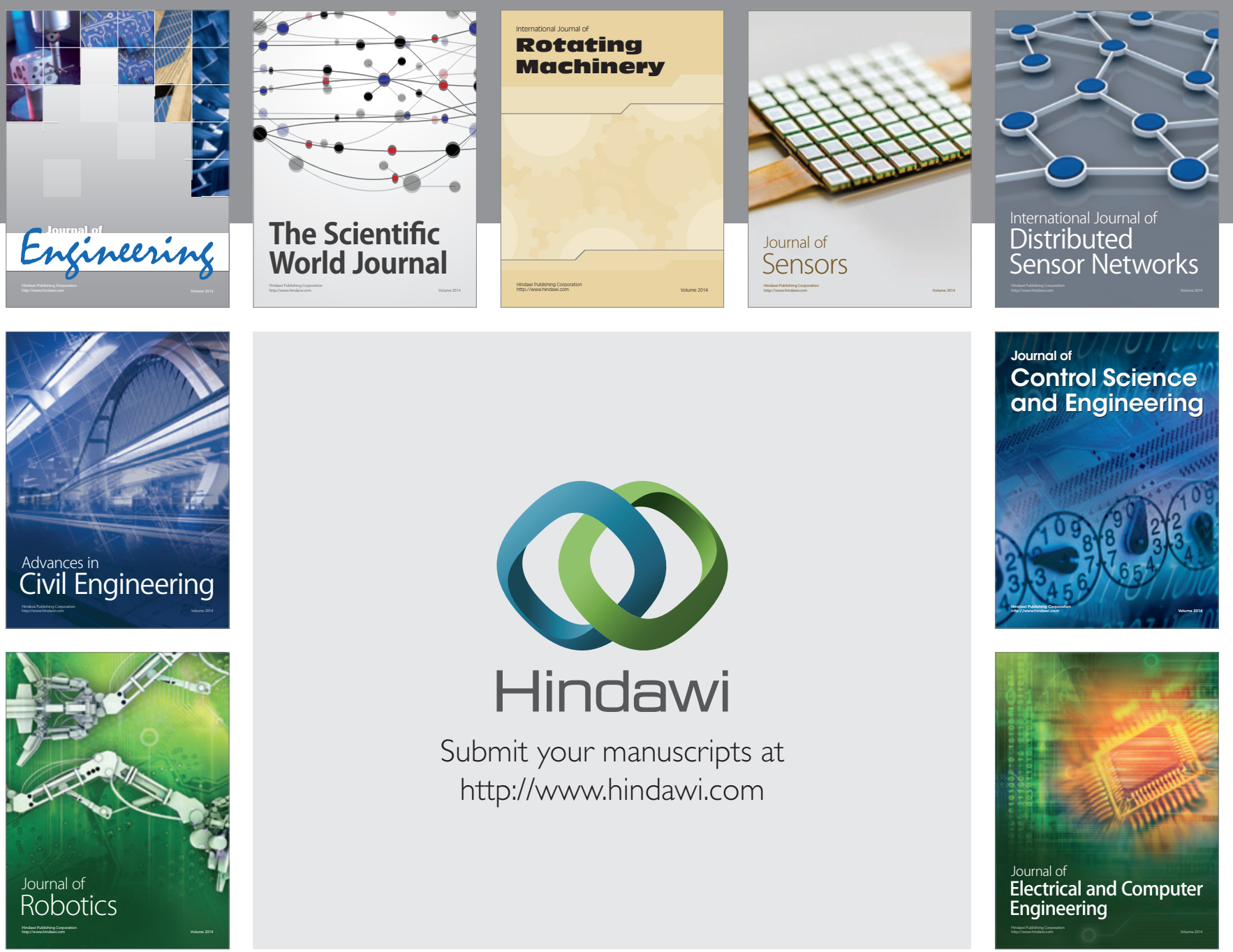

Submit your manuscripts at

http://www.hindawi.com
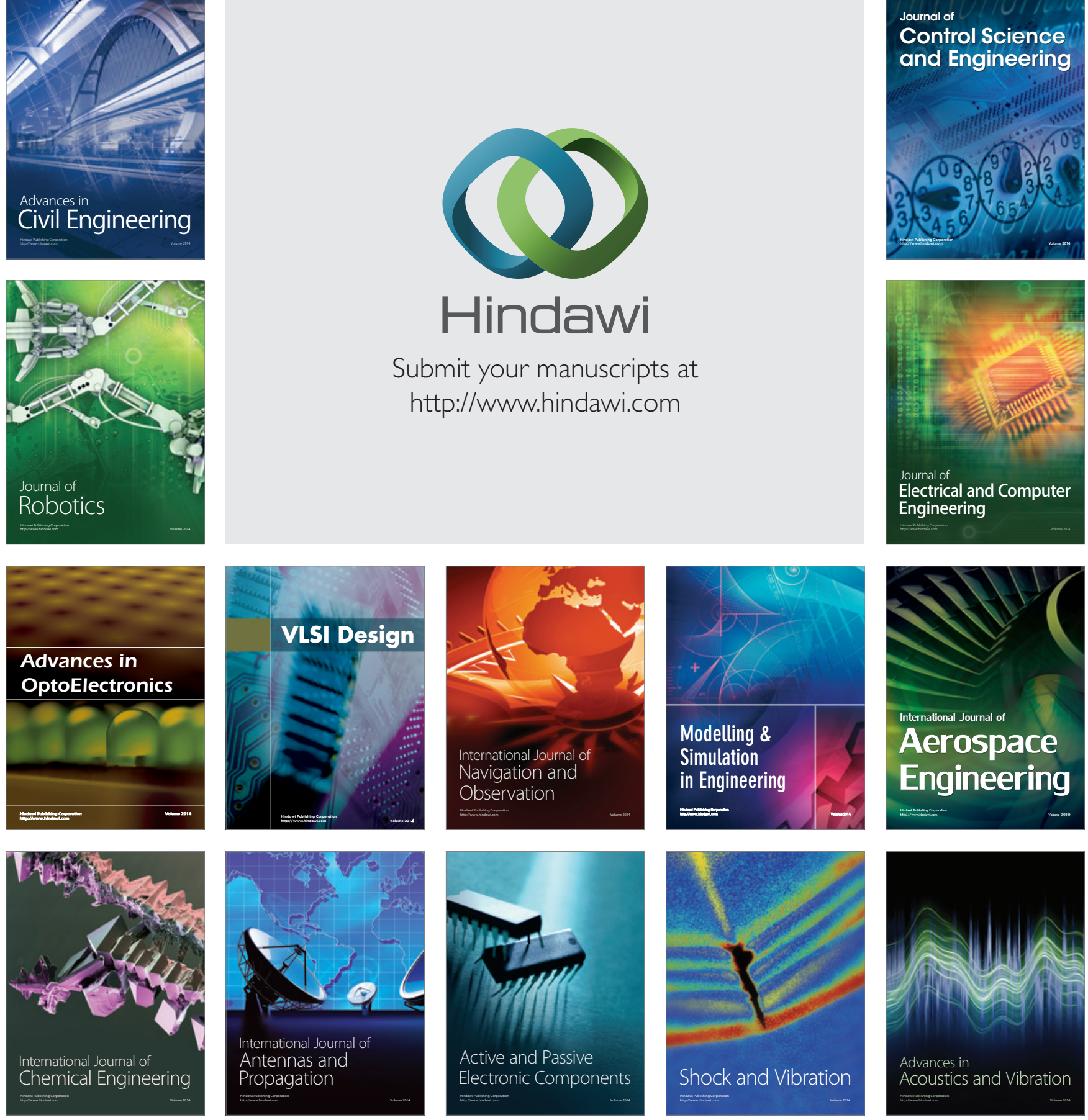